\title{
Prevention of Gossypiboma
}

\author{
Anurag Srivastava $\cdot$ Kamal Kataria $\cdot$ Vasu Reddy Chella
}

Received: 13 March 2013 /Accepted: 26 March 2013 /Published online: 20 April 2013

(C) Association of Surgeons of India 2013

\section{Dear Sir,}

We read the article entitled "Gossypiboma and surgeoncurrent medicolegal aspect - a review" by Biswas et al. [1] in the Indian Journal of Surgery (July-August 2012) 74:318-322.

The authors are right that it is an infrequent but avoidable complication. This complication is a cause for increased morbidity, mortality and financial burden to patients. It is also a source of mental agony, humiliation, financial loss and imprisonment for a surgeon. So, we should always try to avoid this complication. We practice a simple method of avoiding this dreaded problem. As soon the peritoneum is opened, all the single sponges and swabs are removed and are replaced by a pack of five sponges. We tie the tail ends of five sponges together and use it to absorb the blood or other secretions in the peritoneal cavity. Once all the five sponges are saturated, the nurse replaces the "pack of five" or pantch ki mala. Since 1995, we have utilized this method and had no case of gossypiboma. The technique is simple, inexpensive and quick to use in all operation theatres. It eliminates the human error involved in counting the sponges, as the "pack of five sponges" is so big that it is physically impossible to leave inside the abdomen.

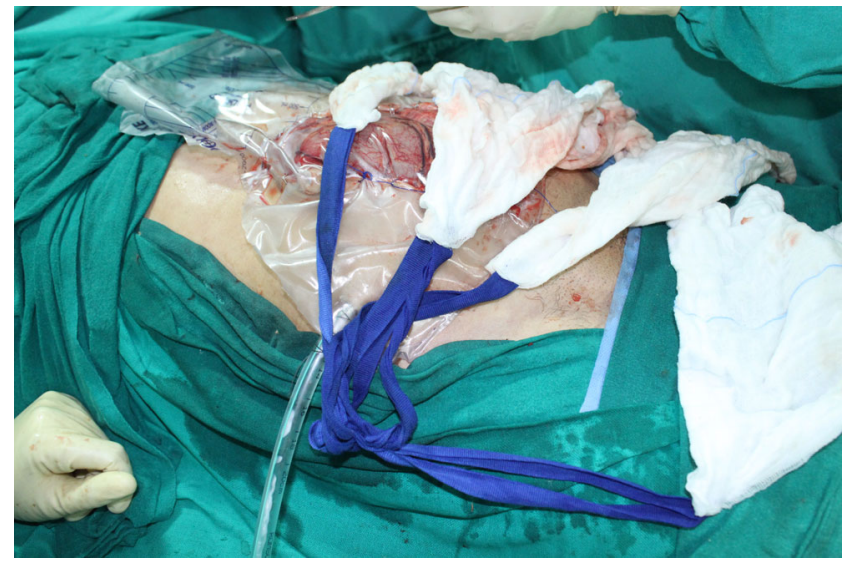

Conflict of Interest None

\section{References}

1. Biswas RS, Gangly S, Saha ML, Saha S, Mukherjee S, Ayaz A (2012) Gossypiboma and surgeon-current medicolegal aspect-a review. Indian J Surg 74(4):318-322
A. Srivastava $(\bowtie) \cdot K$. Kataria $\cdot$ V. R. Chella

Department of Surgical Disciplines, All India Institute of Medical

Sciences, Ansari Nagar,

New Delhi 110029, India

e-mail: dr.anuragsrivastava@gmail.com 